\title{
MIRADAS, ESPACIOS Y RELACIONES EN LA DIDÁCTICA DE LAS ARTES PLÁSTICAS
}

\author{
Silvia BURSET \\ Universitat de Barcelona \\ sburset@ub.edu
}

Hablar sobre la Didáctica de las Artes Plásticas significa mucho más que delimitar objetivos, contenidos, competencias, metodologías y resultados de aprendizaje, a partir de las interrelaciones que se establecen entre los ámbitos de la educación y el arte. Cabe decir que la didáctica, per se, puede definirse como una manera de enfocar y regular los procesos de enseñanza-aprendizaje entre todos los agentes implicados en un contexto determinado; de modo que, indudablemente se generan múltiples miradas situadas en diferentes espacios para establecer relaciones de conocimiento. Este, el conocimiento, entendido en el amplio significado del término y asociado a las acciones de sentir y pensar (si es posible separarlas...). En una entrevista, le preguntaban al filósofo Rafael Argullol si a las personas nos mueven pensamientos o emociones, a lo que él respondió de manera brillante que los pensamientos son emociones enfriadas y las emociones pensamientos sin domesticar.

De este modo, y arguyendo al pensamiento y a la emoción como un binomio indisoluble, la pedagogía de las artes plásticas se nutre de acciones y proyectos desde emociones enfriadas y pensamientos sin domesticar, tanto desde la práctica reflexiva de la propia actuación docente, como desde la investigación e indagación de nuevos enfoques conectados con la realidad circunstancial y el momento vivido.

En el presente monográfico se presentan cinco artículos en los que se pone en valor, el porqué y el para qué de la Didáctica de las Artes Plásticas a través de la argumentación y análisis de, efectivamente, diversas miradas, relaciones y contextos. Todo ello entendiendo que tal y como apuntan Calderón y Hernández (2019) el aprendizaje es siempre múltiple, rizomático y tiene lugar en polifonía con y en diferentes espacios, fuentes e interlocutores puesto que no es un acto individual ni únicamente cognitivo sino que se sitúa en lo social. 
Desde esta perspectiva, resulta interesante observar que, en la Didáctica de las Artes Plásticas, estas no se erigen como contenidos en sí mismos, sino que posibilitan espacios de experimentación y reflexión para "contaminar" otros ambientes u otras, llamadas tradicionalmente, disciplinas.

En el primer artículo, Emma Bosch presenta una mirada que incide en los núcleos conceptuales de la educación visual y plástica en el contexto de la formación inicial de maestros. Tales núcleos son las llamadas "metaclases", que las define como clases autoreferenciales que evidencian las estrategias didácticas de la docente en las sesiones de la asignatura. La autora, a partir de tres propuestas desarrolladas en el aula, muestra cómo la práctica reflexiva no deja de ser un proceso de investigación en la que la experiencia docente se combina con fundamentos teóricos para dar sentido a los mismos a la par que ampliarlos, restringirlos o incluso transgredirlos. Así, la actuación de la docente resulta ser el objeto de estudio de su alumnado bajo la mirada de diferentes prismas o enfoques con contenidos de cariz procedimental o conceptual, como es, por ejemplo, el controvertido tema de la evaluación. En virtud de ello, en el artículo se vislumbra que la evaluación es el eje vertebrador de los objetivos, contenidos y competencias, y además regula los procesos de aprendizaje para consolidarlos a través de un posicionamiento metodológico. Hoy en día, tal y como apunta Francisco Esteban (2019), un buen número de metodologías están asentadas en la defensa de la seguridad y protección del estudiante; no obstante, es preciso que la formación universitaria eduque a buscadores de sensaciones y centre la mirada en cuestiones arriesgadas. El apartado "Mis zapatos me identifican: vivirlo en la propia piel" es un buen ejemplo de cómo la docente conduce a los estudiantes hacia las bases epistemológicas de la asignatura desde lo disruptivo y el vértigo del momento vivido.

El trabajo de Júlia Castell también refleja una nueva manera de aproximarse a la Didáctica de las Artes Plásticas centrada en una experiencia también en el ámbito universitario que se fundamenta en la creación de recursos educativos abiertos, con el objetivo de desarrollar las competencias digitales de los futuros docentes en el tratamiento de la imagen digital. El argumento de Castell se focaliza sobre todo en que el recurso educativo abierto va más allá de ser una fuente de consulta para aprender o saber más, puesto que también se concibe como un espacio democrático y de relaciones para contribuir al avance del conocimiento, así como un camino para acceder al mismo, crearlo y modificarlo hacia la construcción de una política educativa abierta. Este enfoque podemos concebirlo como Amparo Fernández y Javier Paricio (2019) definen un entorno de aprendizaje, que son espacios para la acción, interacción, autorregulación y elaboración personal del conocimiento. La idea de entorno de aprendizaje toma una dimensión más avanzada a través de comunidades de práctica en las que primero participan de forma periférica y dependiente, para ir ganando centralidad y autonomía en sus decisiones y acciones.

En otro espacio, con otra mirada y asistiendo a la creación de otras relaciones, se presenta la investigación de Mar Morón. En el artículo de Morón, se expone la necesidad de atender y entender a las personas con diversidad funcional en el camino de mejorar las habilidades de autoregulación, auto-conocimiento, de percepción, control y eficacia gracias a los procesos de creación artística. En consecuencia, la práctica educativa se considera un eje de formación para llegar a ser objeto de transformación. Por ello, se precisa que el docente actúe como modelo, y en ese sentido, 
y parafraseando a Jacques Rancière (2003), sea un maestro emancipador más que explicador. En este contexto, el arte resulta un espacio ideal para convertir y proyectar un mundo de fantasías en la realidad con la intención de transformarla, vivirla y sentirla de un modo diferente, y tal como expone la autora los procesos artísticos posibilitan un espacio de acercamiento al inconsciente, a sensaciones y pensamientos que emergen en la proyección artística. Morón, como muestra de lo expuesto, describe experiencias desde la investigación-acción, y citando a Stenhouse (1998), valora la figura del profesor como investigador de su propia práctica para mejorar los procesos de enseñanza-aprendizaje.

Los tres artículos a los que hemos hecho referencia hasta ahora ponen el acento en los contextos de educación formal en los que los agentes se relacionan de modos diversos en diferentes situaciones. Ahora, los dos últimos artículos del presente monográfico se contextualizan en espacios de educación no formal.

El primero describe un proyecto de acompañamiento cultural en galerías de arte que no disponen de gabinete pedagógico o atención específica a niños y niñas de las etapas de Educación Infantil y Educación Primaria. Las autoras, $\mathrm{M}^{\mathrm{a}}$ José Lobato y Carmen Salazar, describen la experiencia fundamentada en la Investigación Educativa Basada en las Artes, en las que se establecen interrelaciones entre las personas y las construcciones artísticas, tanto desde lo personal como desde lo colectivo. De acuerdo con esto, los estudiantes universitarios, en el marco del aprendizajeservicio (ApS), se relacionan con niños y familias en el espacio de galerías de arte para contribuir a la aproximación y goce de las manifestaciones culturales. Tal como dice Anne Bamford (2009), la educación artística tiene como objetivo transmitir la relación cultural a los jóvenes y contribuir a su formación emocional y cognitiva.

Y para finalizar, el artículo que cierra el monográfico viene de la mano de Assumpta Cirera, que describe de manera analítica y detallada cómo fue la formación de formadores de acuerdo con la mirada que ofrecía El Laboratorio de las Artes (LdlA) de la Fundación "la Caixa" en el período de 1987-2006, a través de diversos proyectos y recursos dirigidos a maestros y profesores. La mirada a la que aludimos se basaba en una metodología desde la interdisciplinariedad, dando espacio a la experimentación, el diálogo, la reflexión, la participación activa para desarrollar una experiencia vital relacionándose con el entorno. La creación de recursos como las maletas pedagógicas, las publicaciones didácticas, así como los cursos, seminarios, talleres, tertulias de arte y sesiones de trabajo, contribuyeron a que la educación formal y la educación no formal dialogasen para no solo crear espacios de saber, sino para tejer una relación, tal y como apuntábamos al principio, desde lo social. La autora argumenta cómo el LdlA puede resultar un referente de máxima actualidad puesto que el programa aportó una visión integradora e integral de la educación a través del arte, traspasando el límite de las disciplinas.

En la breve descripción de cada artículo que compone el monográfico hemos reiterado los términos miradas, espacios y relaciones; cinco miradas en diferentes espacios para crear relaciones entre los agentes implicados, entre los ámbitos, entre lo que sea, cuando sea y con quien sea. Además, no hay que olvidar que todo conocimiento es un producto de las esperanzas y de los miedos humanos, de las pasiones y del ingenio (Egan y Judson, 2018). 


\section{Referencias bibliográficas}

Argullol, R. (13 de septiembre de 2011). Vivir bien es conseguir que el mañana tenga envidia de hoy. Artículo en periódico. La Vanguardia: La Contra.

Bamford, A. (2009). El factor ¡wuaw! El papel de las artes en la educación: Un estudio internacional sobre el impacto de las artes en la educación ( $1^{\text {a }}$ ed.). Barcelona: Octaedro.

Calderón, N., y Hernández, F. (2019). La investigación artística: Un espacio de conocimiento disruptivo en las artes y en la universidad ( $1^{\text {a }}$ ed.). Barcelona: Octaedro.

Egan, K., y Judson, G. (2018). Educación imaginativa: Herramientas cognitivas para el aula. Madrid: Narcea.

Esteban, F. (2019). La universidad light: Un análisis de nuestra formación universitaria (1a ed.). Barcelona: Paidós Educación.

Fernández, A., y Paricio, J. (2019). Entornos de aprendizaje como espacios para la acción, interacción, autorregulación y elaboración personal del conocimiento. En J. Paricio, A. Fernández e I. Fernández (Eds.), Cartografía de la buena docencia universitaria: Un marco para el desarrollo del profesorado basado en la investigación. (1ª ed. pp. 197-216). Madrid: Narcea.

Rancière, J. (2003). El maestro ignorante: Cinco lecciones sobre la emancipación intelectual. (2a ed.). Barcelona: Laertes. 